\title{
SÍNTESE DE POLI(ADIPATO DE ISOSORBILA) ASSISTIDA POR ULTRASSOM
}

\author{
A. E. POLLONI ${ }^{1}$, P.H.H. ARAÚJO ${ }^{1}$, D. OLIVEIRA ${ }^{1}$, C. SAYER ${ }^{1}$ \\ ${ }^{1}$ Universidade Federal de Santa Catarina, Departamento de Engenharia Química e \\ Engenharia de Alimentos \\ E-mail para contato: andrepolloni@outlook.com
}

\begin{abstract}
RESUMO - O uso do ultrassom como um método econômico e eficaz na produção de polímeros com características diferenciadas como, características da superfície, massa molar, grau de reticulação e incorporação de materiais do tipo orgânico-inorgânico vem recebendo grande atenção nos últimos anos. Assim, este trabalho teve como objetivo estudar a cinética das reações de polimerização em banho termostático e em banho de ultrassom. O sistema reacional estudado foi a policondensação em etapas catalisada por enzima, em massa e em solução. O monômero utilizado nas reações de polimerização (Isosorbídeo) foi escolhido por ser derivado de fonte renovável e por resultar em produtos de grande interesse comercial, podendo ser um possível substituto de monômeros derivados do petróleo. No decorrer do trabalho serão apresentados os resultados em termos de massa molar dos polímeros obtidos ao final do tempo de cada reação. Na polimerização em etapas de isosorbídeo com adipato de dietila catalisada por enzima, a policondensação em massa gerou massas molares baixas (massa molar ponderal média em torno de $1700 \mathrm{~g} / \mathrm{mol}$ ) e o uso do banho de ultrassom não resultou em aumento da massa molar do polímero formado. $\mathrm{Na}$ policondensação em solução de isosorbídeo com adipato de dietila catalisada por enzima o uso do banho de ultrassom resultou em massas molares um pouco mais elevadas em comparação com as amostras produzidas em banho termostático.
\end{abstract}

\section{INTRODUÇÃO}

A síntese de novos materiais poliméricos atrai o interesse de pesquisadores e das indústrias químicas e farmacêuticas e a melhoria contínua de polímeros e de métodos de polimerização existentes ainda é um campo crescente de interesse. A busca pela produção de materiais já existentes, porém com características diferenciadas, como, por exemplo, características da superfície, massa molar, grau de reticulação, incorporação de materiais inorgânicos, entre outras, conduz a um grande esforço na tentativa de encontrar novos métodos para a síntese desses materiais.

Uma técnica que nos últimos anos vem recebendo grande atenção é o uso de ultrassom em reações de polimerização, como um método econômico e eficaz que pode alterar propriedades físicas e químicas de diversos materiais. Baseado na literatura existente, alguns exemplos de alterações induzidas por ultrassom em sistemas poliméricos incluem a dispersão de agentes de enchimento e outros componentes em 
polímeros (como na formulação de tintas), o encapsulamento de partículas inorgânicas em polímeros, modificação do tamanho das partículas, aceleração de reações normalmente lentas, homogeneização mais eficiente em sistemas de polimerização em solução, obtenção de massas molares maiores e com distribuições mais estreitas do que em polímeros obtidos sem o uso de sonificação (Kruus e Patraboy 1985; Price et al., 1995; Suslick e Price, 1999). A utilização de ultrassom em reações químicas, bem como em outras áreas da ciência, é considerada uma tecnologia "verde" devido à sua alta eficiência, baixos requisitos instrumentais, redução significativa do tempo de processamento em comparação com outras técnicas convencionais e por, geralmente, possuir um desempenho economicamente viável (Mason, 2007).

Neste trabalho buscou-se aliar as vantagens encontradas na aplicação da ultrassonificação com a policondensação em etapas de isosorbídeo e adipato de dietila, visando avaliar o efeito do ultrassom na massa molar dos materiais poliméricos obtidos.

\section{MATERIAIS E MÉTODOS}

\section{Materiais}

Adipato de dietila (Sigma Aldrich, 99\%), clorofórmio (Vetec, 99,8\%), ciclohexano (Vetec, 99\%), benzeno (Vetec, 99,5\%) foram utilizados como recebidos. A enzima CAL-B Novozym-435, imobilizada em matriz de poliacrilato foi gentilmente cedida pela Novozymes do Brasil e utilizada conforme recebida. Dianidro-D-glucitol (Isosorbídeo), (Sigma Aldrich, 98\%) foi recristalizado em Acetato de Etila (Vetec, $99,5 \%$ ) e seco em dessecador a vácuo.

Para as reações de polimerização foi utilizado um banho de ultrassom (modelo USC-1880A, Frequência: 37 kHz, 132 watts, 3,8 litros, UNIQUE) preenchido com água destilada.

\section{Preparo das Reações}

Polimerização em etapas de isosorbídeo e adipato de dietila com catálise enzimática em massa: A metodologia empregada para a síntese de poli(adipato de isosorbila) em massa foi adaptada de Juais et al, (2010). Em um balão de fundo redondo de $50 \mathrm{ml}$, adicionou-se 7,31 $\mathrm{g}$ de isosorbídeo, 10,11 g de adipato de dietila e 1,74 $\mathrm{g}$ da enzima CAL-B. Foi então borbulhado $\mathrm{N}_{2}$ e o balão foi fechado hermeticamente. A mistura foi submetida a aquecimento em banho de óleo ou em banho de ultrassom. As reações foram realizadas a 80 e $85^{\circ} \mathrm{C}$. Nas reações assistidas por ultrassom foi utilizado um banho de ultrassom (modelo USC-1880A, Frequência: $37 \mathrm{kHz}, 132$ watts, 3,8 litros, UNIQUE) preenchido com água destilada. A potência do ultrassom foi variada em 52,8; 92,5 e 132 W e nas reações em banho de óleo (modelo C-MAG HS 7, IKA) a agitação magnética foi mantida constante em $300 \mathrm{rpm}$. Os tempos de reação variaram de 120 a 10080 minutos. Após o término da reação, o meio reacional foi suspenso em clorofórmio e filtrado a vácuo para remoção da enzima. A amostra foi então colocada em estufa de convecção forçada a $60^{\circ} \mathrm{C}$, durante 72 horas, para a remoção de solventes e compostos voláteis.

Polimerização em etapas de isosorbídeo e adipato de dietila com catálise enzimática em solução: A metodologia utilizada para a síntese de poli(adipato de isosorbila) em solução foi adaptada de Juais, 2009. Em um balão de fundo redondo de $150 \mathrm{~mL}$ adicionou-se 7,31 $\mathrm{g}$ de isosorbídeo, $10,11 \mathrm{~g}$ de adipato de dietila e 1,74 $\mathrm{g}$ da enzima 
CAL-B Novozyme-435 imobilizada em matriz de poliacrilato. Adicionou-se $65 \mathrm{ml}$ da mistura de solventes ciclohexano:benzeno (6:1), visando obter uma mistura azeotrópica entre os solventes e o subproduto da reação, etanol. Ao balão foi adaptado um sistema Dean-Stark, com o objetivo de recolher o solvente evaporado. O meio reacional foi levado a um banho de óleo ou banho de ultrassom. As temperaturas das reações foram 80 e $85^{\circ} \mathrm{C}$, a potência do ultrassom foi variada $(52,8 ; 92,5$ e $132 \mathrm{~W})$ e o tempo das reações foi de 48 horas. Nas reações com banho de óleo, a agitação do meio foi mantida constante $(300 \mathrm{rpm})$. Ao decorrer da reação, o solvente foi reposto conforme evaporava. Ao término da reação, as amostras foram dissolvidas em clorofórmio e filtradas a vácuo para a remoção da enzima. A fração permeada foi então levada à estufa de convecção forçada a $60^{\circ} \mathrm{C}$ para evaporação do solvente. Em seguida as amostras foram armazenadas para realização das análises posteriores.

\section{Caracterização}

Determinação das massas molares: A massa molar dos polímeros foi determinada por cromatografia de permeação em gel (GPC) utilizando para tanto um Cromatógrafo Líquido de Alta Eficiência (HPLC, modelo LC-20A, Shimadzu) equipado com um detector de RID-10A, em THF, a $35{ }^{\circ} \mathrm{C}$. As amostras foram preparadas solubilizando $0,02 \mathrm{~g}$ de polímero seco em $4 \mathrm{~mL}$ de tetrahidrofurano (THF, Merck), previamente filtrado através de um filtro de teflon com mesh de $450 \mathrm{~nm}$. As distribuições de massa molar e massas molares médias foram calculadas com base em padrões de poliestireno entre $580 \mathrm{~g} / \mathrm{mol} \mathrm{e} 3,8$ milhões $\mathrm{g} / \mathrm{mol}$.

\section{RESULTADOS E DISCUSSÃO}

\section{Polimerização em Etapas de Isosorbídeo e Adipato de Dietila com Catálise Enzimática em Massa em Banho Termostático e em Banho de Ultrassom}

Para o estudo da síntese de poli(adipato de isosorbila), reações de policondensação em massa foram conduzidas em banho termostático e banho de ultrassom. As condições experimentais utilizadas e as massas molares obtidas são apresentadas nas Tabelas 1 e 2:

\begin{tabular}{ccccccc}
\hline & \multicolumn{2}{c}{ Banho Termostático $80^{\circ} \mathrm{C}$} & \multicolumn{3}{c}{ Banho Ultrassom $80^{\circ} \mathrm{C}$} \\
\hline $\begin{array}{c}\text { Tempo } \\
(\mathrm{min})\end{array}$ & $\begin{array}{c}\text { Mw } \\
(\mathrm{g} / \mathrm{mol})\end{array}$ & $\mathrm{Mn}(\mathrm{g} / \mathrm{mol})$ & $\mathrm{PdI}$ & $\mathrm{Mw}(\mathrm{g} / \mathrm{mol})$ & $\mathrm{Mn}(\mathrm{g} / \mathrm{mol})$ & $\mathrm{PdI}$ \\
\hline 120 & 732 & 687 & 1,07 & 648 & 634 & 1,02 \\
240 & 813 & 732 & 1,11 & 678 & 652 & 1,04 \\
720 & 959 & 804 & 1,19 & 796 & 723 & 1,10 \\
1440 & 1215 & 912 & 1,33 & 815 & 734 & 1,11 \\
2880 & 1668 & 1013 & 1,65 & 1182 & 909 & 1,30 \\
10080 & 1699 & 1093 & 1,55 & 2017 & 1694 & 1,19 \\
\hline
\end{tabular}

Tabela 1 - Condições experimentais e massas molares médias obtidos na síntese de poli(adipato de isosorbila) em massa com uso de banho termostático e banho de ultrassom (potência $132 \mathrm{~W}$ ) a $80^{\circ} \mathrm{C}$. 
Banho Termostático $85^{\circ} \mathrm{C}$

Banho Ultrassom $85^{\circ} \mathrm{C}$

\begin{tabular}{ccccccc}
\hline $\begin{array}{c}\text { Tempo } \\
(\mathrm{min})\end{array}$ & Mw (g/mol) & Mn (g/mol) & PdI & Mw (g/mol) & Mn (g/mol) & PdI \\
\hline 120 & 799 & 633 & 1,26 & 559 & 544 & 1,03 \\
240 & 800 & 715 & 1,12 & 672 & 612 & 1,10 \\
720 & 1000 & 916 & 1,09 & 805 & 675 & 1,19 \\
1440 & 1175 & 1022 & 1,15 & 983 & 886 & 1,11 \\
2880 & 1699 & 1115 & 1,52 & 1211 & 982 & 1,23 \\
10080 & 1647 & 1099 & 1,50 & 1614 & 1514 & 1,07 \\
\hline
\end{tabular}

Tabela 2 - Condições experimentais e massas molares médias obtidos na síntese de poli(adipato de isosorbila) em massa com uso de banho termostático e banho de ultrassom (potência $132 \mathrm{~W}$ ) a $85^{\circ} \mathrm{C}$.

Um ponto importante nessas reações de policondensação é a formação de uma molécula de etanol durante a condensação dos monômeros, o etanol neste caso compete com as hidroxilas disponíveis no isosorbídeo, dificultando ou impossibilitando que a reação aconteça. Por isso a remoção do etanol formado do meio reacional para que o equilíbrio da reação seja deslocado na direção dos produtos é de fundamental importância para essas reações. O desafio nestas polimerizações em massa é o fato de que com o decorrer da reação, o meio começa a tornar-se mais viscoso, impedindo que haja uma agitação eficiente do meio reacional, dificultando a transferência de calor e massa entre os componentes da reação e, consequentemente, dificultando a remoção do etanol. A Figura 1 ilustra a síntese do poli(adipato de isosorbila).<smiles>OC1COC2C(O)COC12</smiles>

Isosorbídeo<smiles>CCOC(=O)CCCCC(=O)OCC</smiles>

Adipato de Dietila

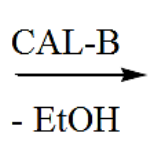

$-\mathrm{EtOH}$

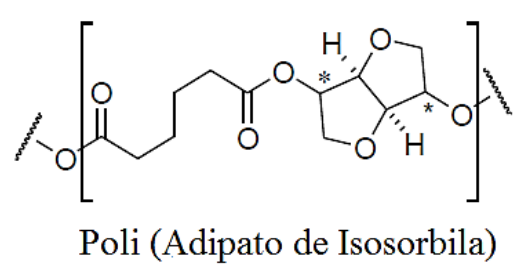

Figura 1 - Síntese de poli(adipato de isosorbila) via policondensação enzimática.

Como pode ser observado nas Tabelas 1 e 2, a policondensação em massa do poli(adipato de isosorbila) levou à obtenção de baixas massas molares ao final do tempo de reação em ambas condições de temperatura $\left(80\right.$ e $\left.85^{\circ} \mathrm{C}\right)$. Isso se deve ao aumento da viscosidade do meio reacional, dificultando a transferência de calor e massa, bem como a retirada do subproduto etanol do meio reacional. Pode-se notar também que as massas molares dos polímeros produzidos em banho de ultrassom não foram maiores que as daqueles produzidos em banho termostático, com exceção da amostra obtida em banho de ultrassom a $80^{\circ} \mathrm{C}$ após 10080 min de reação, que apresentou a maior massa molar (2017 g/mol). Este resultado indica que de um modo geral o banho de ultrassom não foi eficaz para auxiliar na remoção do etanol. Entretanto, cabe mencionar que estes resultados estão de acordo com os obtidos por Juais (2009), onde os autores obtiveram massas molares de $2100 \mathrm{~g} / \mathrm{mol}$ em 7320 minutos de reação, com banho de óleo a $70^{\circ} \mathrm{C}$, utilizando a enzima CAL-B e pressão reduzida e massa molar de 3800 g/mol em 10080 minutos de reação, com banho de óleo a $85^{\circ} \mathrm{C}$ em pressão ambiente. 


\section{Polimerização em Etapas de Adipato de Isosorbila e Adipato de Dietila com Catálise Enzimática em Solução em Banho Termostático e em Banho de Ultrassom}

Nesta etapa do trabalho foram realizadas polimerizações em solução, com destilação azeotrópica, como uma forma de melhorar a cinética da produção de poli(adipato de isosorbila), pois essa técnica de polimerização possibilita a obtenção de viscosidades relativamente baixas durante a reação possibilitando a homogeneização completa do meio, facilitando a remoção do subproduto etanol da reação, deslocando o equilíbrio reacional para o lado dos produtos. As reações foram realizadas a 80 e $85^{\circ} \mathrm{C}$, todas com 48 horas de reação, sendo que o solvente evaporado foi sempre reposto mantendo a razão monômero:solvente constante. Os dados de massas molares obtidas podem ser observados na Figura 2:

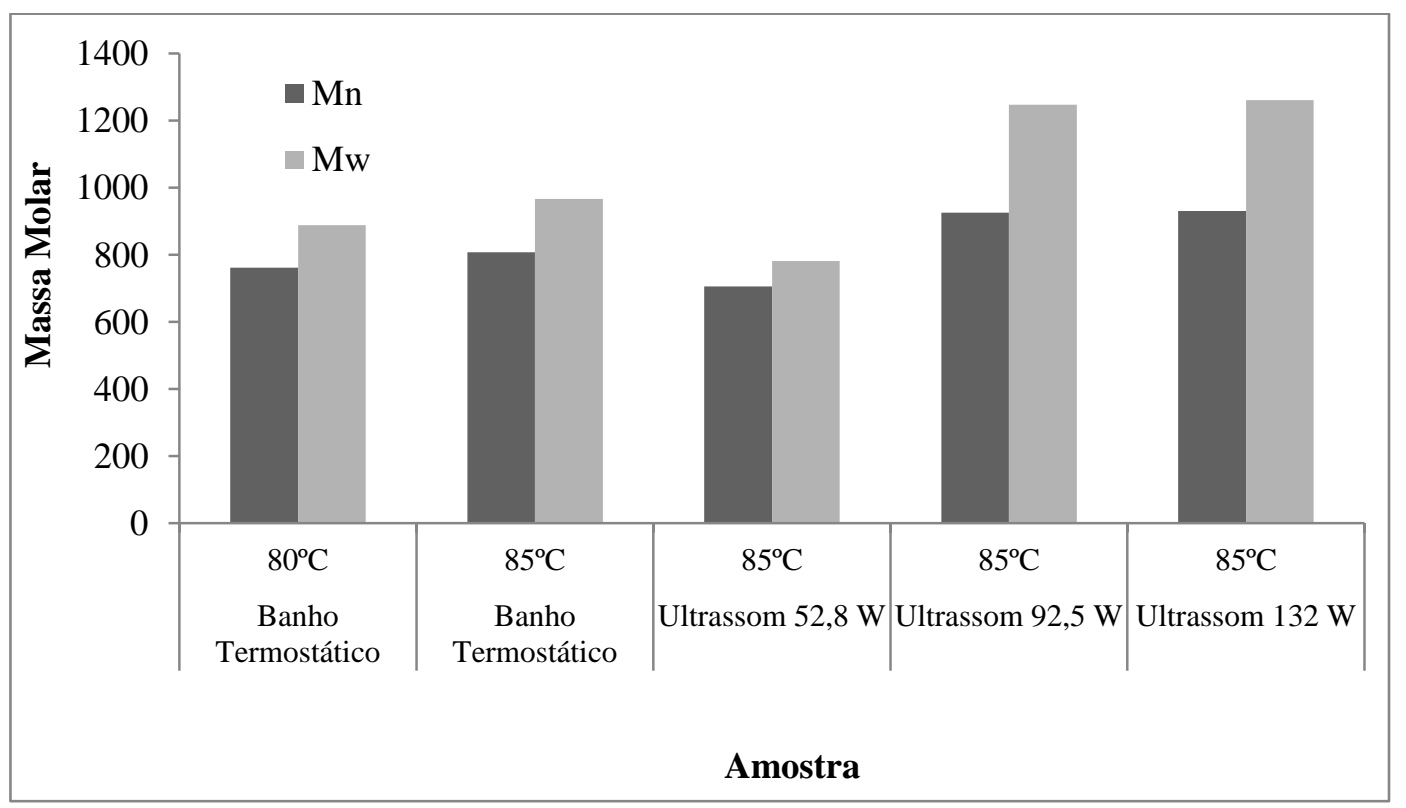

Figura 2 - Massas molares de poli(adipato de isosorbila) produzido em solução com destilação azeotrópica a 80 e $85^{\circ} \mathrm{C}$, em 48 horas de reação.

Nas polimerizações em solução com destilação azeotrópica em banho termostático, os polímeros obtidos também não apresentaram aumento substancial na massa molar. As reações em banho de ultrassom a $92,5 \mathrm{~W}$ e a $132 \mathrm{~W}$ geraram massas molares médias ponderais um pouco maiores (1248 e $1261 \mathrm{~g} / \mathrm{mol}$ respectivamente), indicando, que a utilização do banho de ultrassom conseguiu favorecer levemente a formação do produto nestas reações em solução. Um fato importante observado no decorrer destas reações foi que a temperatura de $85^{\circ} \mathrm{C}$ em banho de ultrassom a taxa de evaporação do solvente, medida pelo condensado formado, foi muito maior do que a evaporação na mesma condição de temperatura no banho termostático. Enquanto que no banho termostático a quantidade de solvente evaporado foi de em média $5 \mathrm{~mL}$ por dia, com o uso do banho de ultrassom a quantidade de solvente evaporada nas mesmas condições foi de $30 \mathrm{~mL}$ por dia. Portanto, uma provável causa desse aumento das massas molares se deve ao fato de que as ondas de ultrassom promovem uma cavitação do meio, formando microbolhas de líquido que implodem ao chegar a um tamanho crítico. Ao ocasionar essas microimplosões, as ondas de ultrassom elevam a temperatura 
das microrregiões ao redor das bolhas, gerando um aumento na temperatura local, mas não causando grande alteração da temperatura global do meio. Esse movimento causado pela implosão das bolhas gera uma homogeneização no meio reacional, aumentando a transferência de calor e massa e favorecendo, neste caso, a remoção das moléculas de etanol, deslocando o equilíbrio da reação para o lado dos produtos. Os resultados encontrados neste trabalho ficaram abaixo dos obtidos por Juais (2009), onde os autores sintetizaram poli(adipato de isosorbila) em solução, com destilação azeotrópica, utilizando ciclohexano: benzeno (6:1) como solvente e enzima como catalisador, obtendo massas molares (Mw) de $6000 \mathrm{~g} / \mathrm{mol}$ em 48 horas de reação e massas de até $32000 \mathrm{~g} / \mathrm{mol}$ em sete dias de reação. Uma possível explicação para essas massas molares menores pode ser que durante a polimerização via catálise enzimática ocorre o aparecimento de limitações difusionais conforme o polímero aumenta sua massa molar. Isso acontece porque a enzima deve gerar continuamente o intermediário acil-enzima por reações com a função éster terminal do polímero em formação e essa geração de intermediários decresce rapidamente à medida que aumenta a massa molar do polímero, porque a difusividade do material no sítio ativo da enzima decresce (Sheldon, 1996).

\section{CONCLUSÕES}

Nas polimerizações em etapas de isosorbídeo com adipato de dietila catalisadas por enzima, pode-se concluir que a policondensação em massa gerou massas molares baixas (massa molar ponderal média em torno de $1700 \mathrm{~g} / \mathrm{mol}$ ) e o uso do banho de ultrassom não resultou em aumento da massa molar do polímero formado. Na policondensação em solução de isosorbídeo com adipato de dietila catalisadas por enzima o uso do banho de ultrassom resultou em massas molares um pouco mais elevadas, porém essas não foram superiores as obtidas nas polimerizações em massa.

\section{REFERÊNCIAS}

JUAIS, D. Produção de polímeros derivados de fontes renováveis via catálise enzimática. Dissertação de mestrado. Programa de pós-graduação em Química. Universidade de São Paulo - USP, São Paulo, 2009.

JUAIS, D., NAVES, A.F., LI, C., GROSS, R.A., CATALANI, L.H. Isosorbide Polyesters from Enzymatic Catalyses. Macromolecules, v. 43, p. 10315-10319, 2010.

KRUUS, P.; PATRABOY, T. J. Initiation of polymerization with ultrasound in methyl methacrylate. Phys. Chem., v. 89, p. 3379 - 3384, 1985.

MASON, T.J. Developments in ultrasound - non-medical. Progress in Biophysics and Molecular Biology, v. 93, p. 166-175, 2007.

PRICE, G. J.; WALLACE, E. N.; PATEL, A. M. Ultrasonically Assisted Synthesis of Silicon-containing Polymers. Special Publication - Royal Society Of Chemistry, v. 166, p. 147-155, 1995.

SHELDON, R.A. Large-Scale enzymatic conversions in non-aqueous media. [Book Appendix]A.M.P Koskinen e A.M klibanov. Enzymatic Reactions In Organic media. Glasglow Blackie Academic \& Professional, 1996. 
SUSLICK, K. S.; PRICE, G. J. Applications of ultrasound to materials chemistry. Annu. Rev. Mater. Sci., v. 29, p. 295 - 326, 1999. 